\title{
A commentary on the relationship between head injury and facial trauma: a case control study
}

\author{
Mohammad Saeid Rezaee-Zavareh
}

Received: 23 August 2013 / Accepted: 11 November 2013 /Published online: 28 November 2013

(C) Springer-Verlag Berlin Heidelberg 2013

Dear Editor,

I read the article "The relationship between head injury and facial trauma: a case-control study" [1] published in your journal. In the article, the authors have evaluated the association between head injury with maxillofacial injuries. This association, especially facial fractures with cranial injuries, has also been evaluated in previous studies and it was suggested to carry out more studies in this field $[2,3]$. The authors have also determined the types of maxillofacial injury in patients with head injury (group I) and compared them with patients without head injury (group II). This cohort, with an evaluation of 2,692 patients with maxillofacial trauma, revealed markers for an increased risk of head injuries and facial bone fractures. However, there are some issues which need clarification. It appears this is not a true "case-controlled" study as claimed in the title of this paper. The authors have mentioned that the age of patients in groups I and II is significantly different and according to Table 2 in the paper, they considered this an important point in adjusting analysis about the association of etiology of trauma with head injury. Age can also have some effects in the association of various facial bone fractures with pattern of head injury. But according to Tables 3, 4, and 5, it seems the adjusted analysis has not considered this as an important point.

\section{References}

1. Zandi M, Seyed Hoseini SR (2012) The relationship between head injury and facial trauma: a case-control study. Oral Maxillofac Surg 17(3):201-207

2. Pappachan B, Alexander M (2006) Correlating facial fractures and cranial injuries. J Oral Maxillofac Surg Off J Am Assoc Oral Maxillofac Surg 64(7):1023-1029, Epub 2006/06/20

3. Haug RH, Savage JD, Likavec MJ, Conforti PJ (1992) A review of 100 closed head injuries associated with facial fractures. J Oral Maxillofac Surg Off J Am Assoc Oral Maxillofac Surg 50(3):218222, Epub 1992/03/01

M. S. Rezaee-Zavareh $(\bowtie)$

Students' Research Committee, Baqiatallah University of Medical

Sciences, Vanak Sq, Tehran, Islamic Republic of Iran

e-mail: Dr_Rezaee@Live.com 